\title{
Pain in relation to emotion regulatory resources and self-compassion: a non-randomized correlational study involving recollected early childhood experiences and insecure attachment
}

\begin{abstract}
BACKGROUND
Pain is common in most diseases and is usually treated by medical and physical approaches (medications, exercise). Limited attention has been given to whether non-medical approaches (such as emotion regulation abilities including self-compassion) can help further reduce the pain experienced. Scleroderma (systemic sclerosis), a painful and complex autoimmune connective tissue and vascular disease, was examined in this study in relation to psychological aspects of pain and the links of pain to (1) early life experiences, (2) current insecure attachment style, (3) physiological arousal (negative, hyper-arousal), and (4) personal emotion regulation (self-compassion). Knowledge about these relationships may help in the treatment of pain.
\end{abstract}

\section{PARTICIPANTS AND PROCEDURE}

Participants (120) from Australia (39) and the United Kingdom (81) completed an online or a hard copy survey; 78 participants remained for analysis after screening.

\section{RESULTS}

We found that poor or limited positive early life experiences and a current insecure (dismissive) attachment style contributed significantly to experiencing elevated levels of pain. We also found that negative early life experiences and limited emotion regulation (low self-compassion) predicted hyper-arousal, which in turn was associated with experienced pain. Insecure dismissive attachment style and hyper-arousal were significantly correlated.

\section{CONCLUSIONS}

These findings suggest that negative childhood experiences and an insecure dismissive attachment style may determine how emotional experiences are regulated or managed by individuals in disease-related pain. Implications include that interventions addressing attachment style and selfcompassion may help reduce pain in the individuals concerned, thus helping supplement the effectiveness of current medication and physical approaches.

KEY WORDS

pain; attachment; hyper-arousal; self-compassion; emotion regulation 


\section{BACKGROUND}

Pain is commonly associated with many diseases, including scleroderma. Pain is usually treated by medical and physical approaches (medications; exercise) that aim to manage or alleviate the pain. Such diseases with associated pain are many and include skin and bone diseases such as arthritis and scleroderma; however, limited attention has been given to whether non-medical approaches can help to further reduce the pain experienced. If we can identify personal resources, symptoms, and experiences that correlate with the experience of pain, we may be able to use the information to develop further treatment strategies that help reduce the pain experience further. Scleroderma (systemic sclerosis) is a painful and complex autoimmune connective tissue and vascular disease that is examined in this paper.

The incidence of those afflicted with scleroderma and its associated pain is growing around the world (Chifflot, Fautrel, Sordet, Chatelus, \& Sibilia, 2008), averaging approximately one individual in every 4000, with the incidence in the USA and Australia reported at 233 to 276 per million, and slightly lower in Europe (e.g., France: 158/million; and England: $88 /$ million). The incidence is increasing with related societal level health costs and personal and pain cost. Government and personal financial costs are considerable. For example, in the United Kingdom, Simm and Barker (2018) have reported on their solution-focused community pain management strategies used in more than 20 pain management programmes in one community pain service - the provision of the services themselves costing greatly, but the results of the interventions showing considerable overall cost savings along with patient and family benefits. They used multidisciplinary teams in line with principles of pain management suggested for communities. We aimed to add further to information on psychosocial aspects that are important in pain management as part of multidisciplinary teams and of special use for some individuals suffering with pain and its management. Scleroderma is one example of a painful illness that may be representative of others. In this paper we draw conclusions about how an individual's early emotional experiences and self and other relationships can influence emotion regulation and therefore the experience of pain. For example, developing positive emotion coping strategies (mindfulness/self-compassion) may lead to a more secure attachment style and reduce the level of pain experienced by people diagnosed with painful illnesses. This is in line with results from interventions showing that ability to regulate emotions (including self-compassion) can be increased through tailored intervention programmes (e.g., Neff, 2003a; Pace et al., 2009; Simm \& Barker, 2018). However, undeniably, changing entrenched attachment styles is not easy (e.g., Bakermans-Kranenburg, Juffer, \& Van IJzendoorn, 1998; Fonagy \& Allison, 2012), though attention to specific areas such as developing sensitivity (Bakermans-Kranenburg et al., 1998; Juffer, Bakermans-Kranenburg, \& Van IJzendoorn, 2014), mindfulness strategies (Neff, 2003a) and mentalization (Fonagy \& Allison, 2012) may be steps towards change and better management of the experience of pain. Our study examined early emotional experiences and emotional regulation strategies in a group of individuals with scleroderma, with implications for other painful disease areas.

\section{PAIN, SCLERODERMA, AND THE BIOPSYCHOSOCIAL MODEL}

Pain is a complex experience involving attention to, and interpretation of, sensory, emotional and cognitive experiences (Lee-Chiong, Gebhart, \& Mattay, 2010). The 'pain perspective in scleroderma' has been addressed in several papers including those by Williams-Judge (2011) from a nursing perspective in The Rheumatologist and by Pope (2011) in Arthritis Care and Research on assessment of pain levels in scleroderma. Pain is an unpleasant physiological and emotional sensation that acts to protect the body from tissue damage (International Association for the Study of Pain - ISAP, 2012). Some pain is 'unexplained', as indicated in a study of unexplained pain following knee replacement (Phillips, Hopwood, Stroud, Dieppe, \& Toms, 2017). The biopsychosocial model emphasises that pain is a multifaceted experience explained by biological factors such as tissue damage, and social and psychological influences (e.g., Gatchel, Peng, Peters, Fuchs, \& Turk, 2007; Keefe, Porter, \& Labban, 2006; Lumley et al., 2011). Pain is more than a sensory neurological experience as the association between tissue injury and the level of pain experienced is weak; therefore the extent to which tissue is damaged is not necessarily an indicator of pain intensity (Lee-Chiong et al., 2010).

Pain is common in scleroderma and is associated with many symptoms such as those involving the skin and musculoskeletal system (Miller, Rehberger, Gunther, \& Schmitt, 2012), Raynaud's phenomenon, and skin ulcers that can become gangrenous, requiring amputation, creating further disability (Giuggioli, Manfredi, Colaci, \& Ferri, 2010). Pain is a predictor of level of physical functioning, disability and psychological factors such as depression (Benrud-Larson et al., 2002; Miller et al., 2012), though how pain is handled is often a private experience differing among individuals (Lee-Chiong et al., 2010).

Pain, hyper-arousal, the immune system, and scleroderma. Hyper-arousal is defined as physical or emotional tension produced by hormones during the fight-or-flight response and is associated with 
the development of autoimmunity (where the in dividual's immune system attacks its own healthy cells and tissues; Schore, 1994). The intensity of the fight-or-flight reaction is generally dependent on an individual's response to a stressor (e.g., Every \& Lating, 2002; Selye, 1976) and ability to adapt to stress exposure (Hammad, Barsky, \& Regestein, 2001). Exposure to unexpected stimuli may produce excessive arousal reactions and increased cortisol (a stress hormone) levels. Individuals with irregular cortisol arousal may be unable to distinguish between physically harmless and threatening stimuli, frequently engaging the fight-or-flight response in non-threatening situations. This condition can overwhelm an individual's resources to accurately process information, decreasing selective attention abilities, resulting in ambiguous meaning and difficultly discriminating between meaningful and insignificant stimuli (Hammad et al., 2001). Research suggests that hyper-arousal is related to the experience of pain (e.g., Rainville, Boa, \& Chretien, 2005) and is assessed in our study by the hyper-arousal scale. This scale was developed by Hammad, Barsky, and Regestein (2001), and measures tendencies to respond intensely to unexpected stimuli and behaviours that involve cortisol arousal.

\section{PAIN, EMOTIONS, AND PSYCHOSOCIAL VARIABLES (EARLY LIFE EXPERIENCES, ADULT ATTACHMENT STYLES)}

The effects of pain have been associated with negative emotions (e.g., Burke, Mathias, \& Denson, 2015; Burns, 2006; Castelnuova et al., 2016; Rainville et al., 2005; Tan, Jensen, Thornby, \& Sloan, 2008). Specifically, Burns (2006) found that emotional responses associated with muscle tension were linked to elevated pain, and Rainville and colleagues found that pain-related anger/frustration and sadness, a desire for relief from pain, perceived lesser control of pain and increases in arousal levels were associated with elevated experiences of pain (Rainville et al., 2005).

Research exploring emotions in relation to how people experience pain has found several psychosocial variables associated with pain occurrence, such that exposure to early life stress may influence an individual's developing brain, including the immune system, the capacity to regulate emotions and reduce arousal in stressful situations, and pain thresholds (Depue \& Morrone-Strupinsky, 2005; Heit, Graham, \& Nemeroff, 1999; Schore, 1994).

Early life stress (a psychosocial variable) including child abuse has been linked to heightened stress in adults, physical illness and pain. Research suggests that individuals exposed to childhood abuse experience an increase in physical symptoms that include gastrointestinal, respiratory, muscular and other types of pain (Thakkar \& McCanne, 2000) and a greater likelihood of developing serious health conditions such as an autoimmune disease, ulcers, cancer, heart disease or diabetes (Sachs-Ericsson, Blazer, Plant, \& Arnow, 2005).

The current study examined pain in individuals' experiences with scleroderma, in relation to the influences of early life experiences (as well as attachment experiences and emotion regulation strategies). Such examination, however, also involved the influence of positive experiences in early childhood, as indicated next.

Early positive memories of warmth and safeness, and their effects. Positive early experiences that engender warmth and safety have been associated with well-being (Schore, 1994), while negative experiences (that engender little or negative warmth experiences) have been associated with low self-compassion and/or the development of selfcriticism and self-judgement (Brewin, Firth-Cozens, Furnham, \& McManus, 1992; Neff, Kilpatrick, \& Rude, 2007), and with poorer psychological outcomes (Irons, Gilbert, Baldwin, Baccus, \& Palmer, 2006; Richter, Gilbert, \& McEwan, 2009). Gilbert and colleagues (2008) suggested that feeling safe and content is a determinant of psychopathology, attachment style and self-evaluation. Positive nurturing experiences that foster feelings of warmth (such as tenderness, kindness and concern) and safeness (feeling safe rather than safety seeking) are associated with a lower risk of developing psychopathology (Mikulincer \& Shaver, 2007).

As indicated, negative early childhood experiences can have detrimental effects on the social functioning, psychological and physical health of individuals. Gilbert (2007) suggested that early life experiences influence gene expression and the biological and psychological functioning of the brain. These early life experiences tend to be expressed in different types of emotion regulation strategies (including self-compassion or its lack) and social communication styles that reflect cognitive and behavioural patterns related to perceptions of threat and safety. The issues in relation to emotion regulation strategies are discussed after attention to another psychosocial variable of interest - attachment styles used by adults - as research has also suggested attachment to be related to wellbeing. Its relation to pain experienced (as in scleroderma) was also of interest in our study.

\section{ADULT ATTACHMENT STYLES, STRESS RESPONSES, HYPER-AROUSAL, AND PAIN}

Adult feelings of security and emotional responses reflect attachment behaviours learned in early childhood, as indicated in early classical studies reported by Bowlby (1969, 1973; republished in 1997, 1998
Pain and selfcompassion 
Richard Edward Hicks, Karen Kearney respectively), and in subsequent associated research such as by Ainsworth and colleagues (e.g., Ainsworth, Blehar, Waters, \& Wall, 1978). There has been much research on attachment and parenting styles and the impacts on later adult attachment (e.g., Juffer et al., 2014). One researcher whose work has been extensive on psychosocial aspects in relation to attachment styles and emotion regulation is Gilbert (e.g., Gilbert, 2001, 2007, 2012; Irons et al., 2006). Gilbert (2012) suggested that the attachment system developed to regulate levels of negative arousal generated by the threat/defence system, consistent with earlier research on attachment and attachment security by Bowlby (1969, reprinted 1997). The attachment experience reflects regulation (or dysregulation) of the stress response and how the right hemisphere of the brain develops. For example, one study of children who receive inadequate emotion regulation experiences showed that they were vulnerable to heightened states of arousal (hyper-arousal), underdeveloped or ineffective coping strategies for regulating emotions, and psychopathology (Schore, 2002).

Bowlby (1973/1998) suggested that people are born with an innate psychobiological system that motivates proximity seeking to attachment figures for protection from threat (safety seeking behaviours; Gilbert, 2012) and thus the reduction of heightened arousal. The failure to reduce arousal levels affects immune responses and future immune functioning, and is a risk in the development of autoimmunity (e.g., Schore, 1994). The availability and responsiveness of attachment figures to act as an emotion regulator affects a child's sense of attachment security, resulting in the development of either a secure or an insecure attachment style (Ainsworth, 1985; Bowlby, 1997). Insecure attachment may invoke a threat response that produces anxiety, fear and distress in similar future situations due to uncertainty about the accessibility and security of attachment figures (Mikulincer \& Shaver, 2007).

Insecurely attached individuals tend to lack the resources necessary to cope successfully, appraising stressful situations as more demanding and difficult to manage than do more securely attached individuals (e.g., Bowlby, 1998; Mikulincer \& Shaver, 2007). Individuals with an insecure, dismissive attachment style (investigated in this study as a variable likely to be linked to defensive/protective behaviours) demonstrate avoidant behaviours and difficulty becoming close to and relying on others. They also can exhibit independent behaviours and a positive view of self; however, underlying insecurity results in avoidance and distancing due to uncertainty as to whether others would be of assistance in times of need (Simpson \& Rholes, 1998). Early attachment stress may result in an individual becoming over-stimulated, creating hyper-arousal in relatively minor situations in adulthood (Van der Kolk \& Greenberg, 1987).
Given this known background about the influences of attachment circumstances in normal development, it could be expected that some circumstances would inhibit the development of appropriate responses at a later stage. However, pain and early attachment experiences do not appear to have been studied extensively and the relationship in different groups of adult individuals with pain also had not been studied extensively, though some data on adult attachment styles, pain and a variety of diseases are available (e.g., Kratz, Davis, \& Zautra, 2012; Martinez, Miro, Sanchez, Mundo, \& Martinez, 2012; McWilliams, Cox, \& Enns, 2000). There has been some research on these aspects in relation to those suffering from scleroderma, and our study now examines the background attachment studies available in relation to scleroderma.

Defensiveness has been reported in previous scleroderma research (e.g., Angelopoulos, Drosos, \& Moutsopoulos, 2001); this may reflect insecure attachment styles, early life stress and ineffective emotion regulation, experiences that are recognised as increasing negative physiological arousal. These circumstances may contribute to the experience of increased pain, as individuals with an under-developed ability to self-sooth (regulate emotional response) may respond defensively and have difficulty feeling safe or content (e.g., Gilbert, 2001; Gilbert, Baldwin, Irons, Baccus, \& Palmer, 2006). Drawing on this research, these fear-related defensive behaviours exhibited by individuals diagnosed with scleroderma suggest a possible hypersensitivity to threat that may initiate protective-defensive-threat arousal, in stress situations involving interpersonal and intrapersonal communications (ways of relating to self and others), that may have developed in early childhood.

Insecure attachment and physical pain. Emotion regulation and early life experiences associated with stressful attachment interactions have been linked to pain reactions. Davies, Macfarlane, McBeth, Morriss, and Dickens (2009) found that insecure attachment styles were associated with approximately twice the experience of chronic widespread pain as other types of attachment. McWilliams et al. (2000) found that individuals experiencing chronic pain due to arthritis and an insecure attachment style reported greater pain intensity and disability as seen also in research by Martinez et al. (2012). Davies et al. (2009), Lee-Chiong et al. (2010), and Thakkar and McCanne (2000) all have suggested that increased pain is associated with psychosocial stress experiences including regulating emotions and factors related to early relational experiences, such as an insecure attachment style and childhood experiences of stress. These factors, however, had not previously been explored in relation to scleroderma pain and were examined in the current study, including studies of self-compassion. 
PAIN AND EMOTION REGULATION: SELF-COMPASSION

Self-compassion is an emotion regulation strategy (Neff, 2003a) that involves being aware of and open to (rather than avoiding) negative experiences and engaging in understanding and kindness toward the self (Neff, 2003a; Neff et al., 2007), rather than harshly judging oneself (as in self-judgement). Selfcompassionate individuals tend to recognise that experiencing suffering and disappointment is part of being human and that people (including oneself) are worthy of kindness and compassionate care (Neff, 2003a). When applying compassion to the self, a kind openness to one's own suffering and pain is essential, allowing an accepting kindness toward less favourable attributes and inadequacies (as in self-judgment).

Self-compassionate individuals tend to have the capacity to view negative experiences from an outside perspective, disengaging from the exaggerated experience of over-identifying with the subjective content and providing kindness to the self from the self (Neff, 2003a). This process reduces the impact of the negative experience and provides opportunities to develop a more holistic view of one's situation (Neff, 2003a). Gilbert (2007) suggested that engaging in mindful self-kindness reduces rumination and lessens the impact of negative affective experiences, by providing opportunities to reduce heightened arousal/threat/stress responses.

This factor of self-kindness or self-compassion was therefore explored in our study, as individuals diagnosed with scleroderma tend to have a heightened stress response when compared with individuals without scleroderma (Freedman \& Ianni, 1983). This response is likely to be linked to feelings associated with fear/stress or threat and the ability to self-sooth, and may reflect an inability to regulate emotions through self-compassion. Therefore it was hypothesised that self-compassion may act as a protective factor for immune functioning (reducing hyper-arousal/ tension trends) and therefore would reduce experienced pain levels for individuals using this emotion regulation strategy. In our study we used the selfcompassion scale as developed by Neff (2003b).

Only a few studies have investigated self-compassion and physiological factors (e.g., Pace et al., 2009; Wren et al., 2011). Pace and colleagues (2009) investigated the relationship of psychosocial stress and physiological reactions of the neuro-endocrine and innate immune systems. The findings suggested that people who engaged in more compassion-focused meditation scored lower on physiological responses (such as cortisol - arousal levels) and psychological measures (such as of distress and anxiety), suggesting that stress-induced immune and behavioural responses (arousal) may be moderated by compas- sion-focused meditation (Pace et al., 2009). A study on age of onset of breast cancer and self-compassion found that greater self-compassion was related to lower levels of hyper-arousal and a later onset of disease (Kearney \& Hicks, 2017). Therefore, it appears from the available research that strategies high in self-compassion are likely to produce positive physical and psychological health outcomes (Kearney \& Hicks, 2017; Neff, 2003a; Pace et al., 2009). Risk factors in the development of autoimmunity have been explored in the literature; however, factors that may protect an individual from elevated (threat-related) arousal and exacerbated experiences of pain have not previously been explored in detail and certainly not in relation to scleroderma. We examined this relationship to experienced pain in individuals diagnosed with scleroderma.

\section{BACKGROUND RATIONALE, AIMS AND HYPOTHESES}

Stress experiences can occur at any age and may influence how emotions are regulated and whether negative physiological arousal responses occur that can affect immune system functioning. Early childhood experiences, whether positive or negative, may influence how individuals experience and manage stress. Some interpersonal and intrapersonal experiences may influence emotional responses that are not helpful in reducing arousal. The individual may attach certain meaning to current communications/experiences as a result of experiencing negative messages from others in childhood or other attachment relationships which may result in self-judgment/criticism and a diminished capacity to reduce negative arousal. These negative interpersonal/intrapersonal experiences may increase negative arousal and tension and are responses associated with elevated pain (Rainville et al., 2005). Therefore, engaging in strategies that effectively reduce distress and negative physiology/tension such as self-compassion may provide benefit in relation to how pain is experienced.

Our study and its aims. As the development of effective emotion regulation strategies that reduce arousal tend to be influenced by positive nurturing experiences in early life and the development of a secure attachment style, it was hypothesised that negative early relational experiences deficient in compassion and safety and the utilization of an insecure attachment style would be related to elevated pain. These variables were also hypothesised to correlate with ineffective emotion regulation strategies (low self-compassion) and elevated arousal (hyperarousal). The development of more effective ways of managing negative experiences; through greater self-understanding and compassion, may provide more beneficial outcomes in relation to pain expe-
Pain and selfcompassion 
Richard Edward Hicks, Karen Kearney rienced. The purpose of our study was to determine whether scleroderma-related pain was related to early nurturing experiences, attachment style, hyper-arousal and self-compassionate/emotion regulation strategies.

This study therefore hypothesised that greater levels of pain would be predicted from lower experiences of warmth and safety as a child, and greater levels of dismissive attachment. The regression equation used physiological pain as the dependent variable (measured by the Scleroderma Health Assessment Questionnaire; Steen \& Medsger, 1997); and emotional relational experiences, EMWS (Early Memories of Warmth and Safeness Scale; Richter et al., 2009), and dismissive attachment (Relationship Scale Questionnaire; Griffin \& Bartholomew, 1994) as independent variables. Self-compassion (SelfCompassion Scale; Neff, 2003b) and hyper-arousal (Hyper-arousal Scale; Hammad et al., 2001) were also hypothesised to correlate with EMWS and dismissive attachment. These variables were investigated as factors that may provide some insight into how relational experiences are perceived, that is, how an individual relates to self as a result of interactions with significant others and how these experiences impact on physiology and pain. Therefore, we hypothesised that those engaging in higher self-compassion and who experience lower hyper-arousal levels would report higher early nurturing experiences and lower dismissive attachment styles, while those engaging in lower self-compassion and who experience greater negative physiological arousal would report lower early nurturing experiences and greater dismissive attachment, experiences hypothesised to be related to elevated pain.

\section{PARTICIPANTS AND PROCEDURE}

\section{PROCEDURE}

Several scleroderma organisations internationally were involved in promoting this study to members diagnosed with scleroderma. These organisations included the Queensland, and the Australian Scleroderma Associations, and the United Kingdom Scleroderma Society. These non-profit organisations work to provide education and support for members with scleroderma and their families. Approval was obtained from the various associations' committees responsible for scleroderma research once the survey and explanatory letter had been viewed and discussed. Participants in Australia were recruited through newsletters published by the Australian, and Australian State Scleroderma Associations, such as Queensland and Victoria and by the primary researcher within South East Queensland (Sunshine Coast, Brisbane and Gold Coast) at scleroderma meetings to complete an online or hardcopy version of the survey. Australian participants who had no online access received a hardcopy version of the questionnaire. These participants were recruited from phone enquires and emails as a result of advertisements in scleroderma newsletters and magazines or at scleroderma meetings. A questionnaire with a stamped addressed envelope (to the supervisor of this project in Australia) was forwarded to interested participants by mail or handed to participants at meetings. A written explanatory letter containing information about the purpose, procedure, where questions/complaints could be directed, risks and benefits of the research project and confidentiality of participants was attached as a cover page to the online and hardcopy versions. The survey required approximately 50-60 minutes to complete.

In the United Kingdom information about the study and the survey including a written explanatory letter from both the researchers and the United Kingdom Scleroderma Society itself was forwarded by the trustee of the Society to 231 members who had been diagnosed with scleroderma. The project was approved by Bond University's Human Research Ethics Committee and received approval from the Scleroderma Society Ethics Committee in the United Kingdom and the Queensland and Australian Scleroderma Associations.

\section{PARTICIPANTS}

Male and female adults aged 18 years and over diagnosed with scleroderma were invited to participate in this research project. Participants were asked several demographic and health questions, such as the country resided in, gender, current age and age diagnosed with scleroderma.

\section{MEASURES}

\section{Psychosocial stress: early nurturing experiences}

Richter and colleagues (2009) developed the Early Memories of Warmth and Safeness scale (EMWS) to measure negative childhood experiences. The EMWS scale was selected for this study as it was designed to measure the recall of feelings associated with warmth and safety as a child and may be a better indicator of early negative life experiences than recalling specific negative event(s) in childhood (Richter et al., 2009). Richter and colleagues suggest that how individuals respond to an event (both physiologically and emotionally) may be a better indicator of threat than recalling the stressful event itself, as some individuals may recall parents as kind and available but still feel fearful and lack a sense of belonging. Oth- 
ers may have experienced negative events but felt they managed and coped well (Richter et al., 2009). The recall of positive or negative feelings associated with early rearing experiences generally relies on the recollection of an individual's own inner experiences, rather than recalling events related to others' behaviour, as an indicator of stress experienced. Recall of affect in relation to childhood memories may therefore explain feelings of threat not accounted for by the recall of any particular stressful event. [This view of exploring an individual's experience of threat was used in this study to measure the scleroderma participant's reporting of early life exposure to warmth and safety, using the scale by Richter, Gilbert, and McEwan (2009), as an individual's capacity to regulate arousal early in life influences immune responses and future immune functioning]. Early adverse experiences may influence vulnerability in numerous areas of functioning involving threat/ arousal, including regulating emotions and arousal or hyper-arousal - accentuating the experience of stress (Schore, 1994).

Early Memories of Warmth and Safeness Scale. The EMWS scale is a 21-item self-report, 5-point Likert scale (e.g., 0 - no, never, 2 - yes, sometimes and 4 - yes, most of the time). Items include "I felt safe and secure", "I felt a sense of belonging", "I felt cared for". This scale assesses emotional memories of an individual's childhood and preverbal or nonverbal experiences of stress. The EMWS scale focuses on recall of one's own emotional experiences while most other measures focus on recall of others' behaviours; recall of positive emotions (or deficits) was found to be a better predictor of psychopathology and styles of self-criticism than recall of parental behaviour. The EMWS scale has good psychometric properties (high Cronbach's $\alpha$, retest reliability, divergent and predictive validity, and in the current study had a Cronbach $\alpha$ coefficient of above .90).

\section{Attachment: Relationship Scale Questionnaire (RSQ)}

The Relationship Scale Questionnaire (Griffin \& Bartholomew, 1994) comprises 30 items each rated on a 5-point Likert scale (e.g., 1 - not at all like me, 3 - somewhat like me, and 5 - very much like me). This self-report measure was developed to assess a number of insecure attachment styles such as dismissive and fearful. Examples of items include "I find it difficult to depend on other people", "It is important for me to feel independent", "I find it easy to get emotionally close to others", "I want to merge completely with another person". The questionnaire has good internal consistency ranging from .85 to .90 (Griffin $\&$ Bartholomew, 1994). The current study revealed a Cronbach's $\alpha$ coefficient for dismissive attachment (5 items) of .65; the mean inter-item correlation at .28 was also satisfactory (Briggs \& Cheek, 1986).

\section{Self-compassion: Self-Compassion Scale}

The Self-Compassion Scale (Neff, 2003b) has been widely used to measure this construct. This scale used in the current study assesses the three major aspects of self-compassion: self-kindness, common humanity and mindfulness. Self-kindness refers to treating oneself with warmth and care without engaging in self-judgment. Common humanity requires an ability to understand one's own suffering or inadequacies as part of shared human experiences, rather than feeling alone or isolated. Mindfulness involves a capacity to engage in a more balanced holistic perspective rather than over-identifying with negative experiences and is regarded as a protective behaviour for experiences of anxiety (Neff, 2003b).

The Self-Compassion Scale (Neff, 2003b) is a 26-item, self-report, 5-point Likert (e.g., 1 - almost never and 5 - almost always) emotion regulation measure that contains three components. Self-kindness/Self-judgment (being kind and understanding toward oneself rather than judgmental or critical: 10 items); Common humanity/Isolation (viewing one's negative experiences as a normal part of the human condition rather than experiencing suffering in isolation: 8 items); and Mindful acceptance/Over-identifying (being open to and accepting of one's situation rather than over-identifying with painful thoughts and feelings: 8 items). Examples of items include "When things are going badly for me, I see the difficulties as part of life that everyone goes through", "When I think about my inadequacies, it tends to make me feel more separate and cut off from the rest of the world", "I try to be loving towards myself, when I'm feeling emotional pain", "When I fail at something important to me, I become consumed by feelings of inadequacy". This scale has good psychometric properties (construct, content, convergent and discriminant validity; test-retest reliability) and is a valid theoretical measure of self-compassion (Neff, 2003b). Our study obtained a Cronbach $\alpha$ coefficient for selfcompassion of above .70 .

\section{Arousal (reactive): Hyper-arousal Scale}

The Hyper-arousal Scale (Hammad et al., 2001) is a 26-item self-report 5-point Likert scale that measures tendencies to introspect or think about feelings by responding intensely/highly reactively to unexpected stimuli and other behaviours that involve cortisol arousal. The scale contains items such as "Bright lights, crowds, noise or traffic bother me", "I think a lot about feelings", "My mind is always going", "I take things personally", "I am overly conscientious". This scale has good psychometric properties (predictive and construct: Hammad et al., 2001). Analysis in the current study revealed a Cronbach's $\alpha$ coefficient for hyper-arousal above .80 . The subscale reactive hyper-
Pain and selfcompassion 
Richard Edward Hicks, Karen Kearney arousal (correlated variable for EMWS and dismissive attachment) was .52 (3 items) with an acceptable inter-item correlation mean of 0.26 (Briggs \& Cheek, 1986). Participants recorded responses to 26 questions related to how they would respond in certain situations (e.g., 0 - not at all true to 5 - completely true). Hyper-arousal scale scores correlate with several EEG measures of arousal including frequency spectral and evoked potential measures (Hammad et al., 2001). Hyper-arousal scores signify increased general cerebral responsiveness but decreased selective attention, indicating openness to stimuli and difficulty distinguishing between physiologically harmless and threatening sensations. This situation may create an information overload and result in difficulty adapting to recurring stimuli. A decrease in selective attention may create ambiguity as to the meaning to be attributed to the perceived experience, resulting in the development of an adversity management system (Hammad et al., 2001).

\section{Scleroderma pain: Questionnaire}

The Scleroderma Health Assessment Questionnaire (SHAQ; Steen \& Medsger, 1997). The SHAQ provides a disability index measuring eight areas of functioning including arising, dressing, grooming, hygiene, eating, walking, reach, grip and activity and is used to measure severity of disability. Item responses range from 0 , which indicates without any difficulty, to 3 , indicating unable to do it. The index contains questions such as "Are you able to open jars previously opened?” Specific scleroderma-related symptoms of pain, Raynaud's, finger ulcers, breathing and intestinal problems are measured using a single analogue visual scale (for each symptom) ranging from 0 , indicating no limitation, to 100 , indicating very severe limitation. Individuals were asked to indicate a number between 0 and 100 that indicated the degree of pain (or incapacity) experienced. The variable pain in this study was measured using this scale. Analysis in the current study revealed Cronbach's $\alpha$ coefficients for the total SHAQ to be above .90 , indi-

\section{Table 1}

Summary of the multiple regression analysis predicting scleroderma pain

\begin{tabular}{lccc}
\hline Variable & $B$ & SEB & $\beta$ \\
\hline Pain & & & \\
$\quad$ EMWS & -0.36 & .12 & $-.34^{* *}$ \\
$\quad \begin{array}{l}\text { Dismissive } \\
\text { attachment }\end{array}$ & 1.45 & .66 & $.24^{*}$ \\
Total $R^{2}$ & $.19^{* *}$ & & \\
\hline Note. ${ }^{*} p<.05,{ }^{* *} p<.01$. & &
\end{tabular}

cating close relationships between all items on the scale (from the pain item through the physical items). The SHAQ has generally been found to have good psychometric properties (Johnson, Hawker, \& Davis, 2005) and to be highly useful in practice (e.g., Pope, 2011; Williams-Judge, 2011).

\section{RESULTS}

\section{OVERVIEW OF ANALYSIS}

Analysis was performed using SPSS version 23. Descriptive statistics for each of the continuous variables were obtained. Pearson's product-moment correlation coefficients were calculated for the scales to establish the relationships between the dependent variable (pain) and the independent variables [early memories of warmth and safeness (EMWS) and insecure attachment style and this relationship to emotion regulation strategies (self-compassion) and physiological responses (hyper-arousal)]. Multiple regression analyses were considered appropriate to meet the main hypotheses.

Correlations and multiple regression analyses examining whether EMWS and an insecure attachment style would predict greater scleroderma-related pain revealed meaningful relationships between pain and EMWS $(r=-.37, p=.002)$, and dismissive attachment style $(r=.28, p=.017)$, and demonstrated that EMWS and attachment significantly accounted for $43.7 \%$ (adjusted $R^{2}=16.7 \%$ ) of the variance, $F(2,68)=8.04$, $p=.001$, in pain related to scleroderma symptoms. The regression coefficients demonstrated that EMWS $\left(\beta=-.34, p=.003, s r^{2}=11.2 \%\right)$ and dismissive attachment $\left(\beta=.24, p=.032, s r^{2}=5.7 \%\right)$; were significant unique predictors of the pain experienced by individuals diagnosed with scleroderma.

Results for predictor variables for pain are presented in Table 1.

Pain: Results demonstrated that individuals diagnosed with scleroderma who experienced low warmth and safety as a child and engaged in a dismissive style of relating reported greater experiences of pain.

The significant independent variables for pain (reactive hyper-arousal, EMWS, dismissive attachment and self-judgement) were also investigated. Pearson's bivariate correlations revealed significant relationships between dismissive attachment and reactive hyper-arousal (subscale of hyper-arousal), $r=.41, p=.001$, and self-judgement (negative subscale of self-compassion), $r=.31, p=.010$; and EMWS was significantly related to self-judgment, $r=-.36, p=.003$, and reactive hyper-arousal, $r=-.36$, $p=.003$. Multiple regression analysis demonstrated that the variables self-judgment and reactive-hyperarousal significantly accounted for $43.9 \%$ (adjusted $\left.R^{2}=16.7 \%\right)$ of the variance, $F(2,63)=7.51, p=.001$, 
in EMWS related to scleroderma pain symptoms. The regression coefficients demonstrated that selfjudgment $\left(\beta=-.27, p=.027, s r^{2}=6.6 \%\right)$ and reactive hyper-arousal $\left(\beta=-.26, p=.034, s r^{2}=6.0 \%\right)$ were both significant predictors of EMWS in individuals diagnosed with scleroderma.

Multiple regression analysis also demonstrated that the variables reactive hyperarousal and selfjudgment significantly accounted for $44.5 \%$ (adjusted $\left.R^{2}=17.4 \%\right)$ of the variance, $F(2,65)=8.01, p=.001$, in dismissive attachment related to scleroderma pain symptoms. The regression coefficients demonstrated that reactive hyper-arousal $(\beta=.34, p=.006$, $\left.s r^{2}=11.2 \%\right)$ but not self-judgment was a significant unique predictor of dismissive attachment experienced by individuals diagnosed with scleroderma.

The results demonstrated a relationship between experiences of warmth and safety in childhood (EMWS) and low/negative self-compassion (selfjudgment) and hyper-arousal (reactive hyper-arousal). That is, lower experiences of early nurturing related to a lower capacity to engage in self-compassion and therefore more negative interactions with oneself and more negative physiological arousal. The results also showed a positive relationship between insecure dismissive attachment and experiences of negative physiological arousal (reactive hyper-arousal).

Results for predictor variables for EMWS and dismissive attachment are presented in Table 2.

\section{DISCUSSION}

\section{FINDINGS, AND PREVIOUS RESEARCH}

These findings support both parts of the main hypothesis: the first part, that emotional stress experienced at an early age (EMWS) and a current insecure attachment style (dismissive attachment) together would be significantly related to elevated pain; and the second part, that relational stress (EMWS and insecure attachment style) would be correlated with ineffective emotion regulation strategies (negative self-compassion) and also with elevated negative physiological responses (reactive hyper-arousal). Reactive hyper-arousal was also a predictor variable of dismissive attachment. These findings are consistent with the biopsychosocial perspective of pain that includes physical, emotional, cognitive and related previous experiences; psychological factors; and aspects that involve sensations, attention and interpretation (Lee-Chiong et al., 2010).

Findings in the current study are consistent with research by Gilbert (2008), Sachs-Ericsson et al. (2005), and Thakkar and McCanne (2000), which suggests that early life stress involving a lack of warmth and safety is linked to elevated levels of stress in adulthood, and to physical illness. Exposure to early life stress can influence emotions and physiology as
Table 2

Summary of the multiple regression analysis for variables EMWS and dismissive attachment

\begin{tabular}{lccc}
\hline Variable & $B$ & SEB & $\beta$ \\
\hline EMWS & & & \\
$\quad$ Self-judgement & -1.49 & 0.66 & $-.27^{*}$ \\
$\quad$ Reactive & -2.35 & 1.09 & $-.26^{*}$ \\
$\quad$ hyper-arousal & & & \\
$\quad$ Total $R^{2}$ & $.19^{* *}$ & & \\
$\begin{array}{l}\text { Dismissive } \\
\text { attachment }\end{array}$ & & & \\
$\quad$ Reactive \\
hyper-arousal
\end{tabular}

Note. ${ }^{*} p<.05,{ }^{* *} p<.01$.

well as the capacity to regulate emotions and arousal levels, and pain thresholds (Depue et al., 2005; Heit et al., 1999; Schore, 1994). Findings in the current study suggest that individuals with scleroderma who report negative early life experiences and a dismissive attachment style may suffer elevated levels of pain resulting from the emotions involved in the interpretation of their interpersonal and intrapersonal experiences. This suggests that negatively interpreted experiences affect the immune system (via hyper-arousal) and the production of fight-or-flight inflammatory responses which in turn exacerbate scleroderma symptoms and the experience of pain.

Other research findings on the relationship of early life experiences and their later life effects in the handling of pain are also supported by our findings in relation to scleroderma sufferers. For example, Thakkar and McCanne (2000) in a comparative study of women sexually abused and those not abused; Kearney and Hicks (2017) on how the experience of pain in breast cancer can be related to adverse early life experiences and an inadequate emotion regulation strategy (low self-compassion); and Keefe, Porter, and Labban (2006) on how couples manage pain (or do not) all show consistency in terms of early life experiences.

Studies of attachment styles and their effects have also been numerous, including findings by Davies et al. (2009) that chronic pain is associated with insecure attachment style (our study supported this finding, suggesting that the way we relate to others via our feelings about ourselves can contribute to the experience of elevated pain). Other studies linking adult attachment styles and pain include those of Forsythe, Romano, Jensen, and Thorn (2012) on marital attachment styles and associated experiences of pain; Kratz et al. (2012) on attachment, coping and pain in women; and McWilliams et al. (2000) in relation to arthritis.
Pain and selfcompassion 
There is a gathering body of evidence, now including the study of scleroderma and its associations, indicating that early life experiences and current attachment styles are related to levels of pain that may be experienced by affected individuals. Inadequate emotion regulation strategies such as limited self-compassion also appear strongly related to the pain experienced.

\section{IMPLICATIONS OF THE FINDINGS}

Richard Edward Hicks, Karen Kearney

The implications are that early stress experiences are likely to compromise an individual's ability to manage the emotional and cognitive aspects associated with pain, resulting in elevated experiences of pain. Pain recognised as a subjective and physical experience differs among individuals (Lee-Chiong et al., 2010), and in the current study was associated with several factors including interpersonal and intrapersonal experiences, consistent with suggested models of pain development and management (cf., Romeo, Tesio, Castelnuovo, \& Castelli, 2017). The intensity of the pain experienced in the current study of individuals suffering scleroderma was linked to early childhood experiences associated with feelings of insecurity and limited resources to manage emotions with self and others. Early experiences associated with affective states of safety and nurturing are important factors in relation to emotion regulation strategies and coping. Engaging in a dismissive way of relating to significant others reduces the opportunity for the individual diagnosed with scleroderma to engage others as external emotion regulators in times of stress/distress to reduce arousal levels. This way of relating limits the individual's calming resources to self-reliance and limits the capacity to self-sooth. The ability to reduce arousal and self-sooth may therefore be compromised, and in the current study the compromised situation was related to low self-compassion (an inadequate emotion regulation strategy) which may then have generated further negative emotions and increased negative (reactive) physiological arousal.

In the current study adverse early life experiences and the inability to work together with others to reduce arousal are experiences that were associated with elevated pain in our scleroderma sample. Individuals who have an under-developed ability to self-sooth may respond defensively and have difficulty feeling safe or content, which may explain the findings of Hyphantis et al. (2007) suggesting that individuals with scleroderma tend to be defensive. That is, early life experiences that do not provide opportunities to experience nurturing and safety and learn strategies such as self-compassion may augment the development of a reactive threat system. This reactive threat system arises as a result of negative experiences and ineffective strategies that increase arousal (such as defensiveness and negative self-judgment) and may therefore impact on how individuals respond to and experience pain.

Arising from these findings and discussion is the question: What can be done to intervene and/or assist those suffering such pain? Already there are many approaches, mostly related to the medical and physical treatment modalities, but not a few relating to psychosocial intervention strategies to enable better management of pain. It matters to many (as indicated by Jensen \& Turk, 2014), and certainly it matters to those of us who suffer from pain or whose family members suffer from pain. Many psychosocial intervention programmes have been developed, such as those described in the following literature: Castelnuovo et al., 2016; Kaiser, Mooreville, and Kannan, 2015; Eyer and Thorn, 2016; and Simm and Barker, 2018. However, not many of these programmes incorporate attention to emotion regulation (self-compassion) strategies or to responding to recollections of early adverse experiences, or to current attachment styles and their effects. Our study suggests that individuals dealing with pain may well be helped if these areas are a part of their own background of life experiences.

There are other health, family and financial implications of the results. Engaging in effective emotion regulation strategies such as self-compassion may provide not only personal benefits to the individual but also financial benefits to the health system. The benefits of engaging in self-compassionate emotion regulation strategies would provide advantages for the individual, the family and the general community. Psychologists and health counsellors could screen for early life adversity and offer counselling to assess attachment style and emotion regulation to help patients consider more adaptive strategies to cope with emotion regulation, the chronic disease, and the pain.

\section{LIMITATIONS}

Reporting of early childhood experiences in the current study required the recollection of past events. Recounting these events may be impeded by individuals' ability to accurately remember how they felt at a very early time in their life. The current paper reported results in relation to scleroderma. Applications to other illnesses where pain is involved also need to be examined as similar results may be found and provide a further base to help in relation to the pain experienced. For example, studies of other painful illnesses such as breast cancer (Kearney \& Hicks, 2017) have shown similar results, but further studies would help strengthen the case for attention in treatment to psychosocial variables such as those we have examined in the current study (early life experiences of warmth and safety or its lack, current attachmentrelationship styles, and self-regulation/self-compassion strategies). 


\section{CONCLUSIONS}

Pain involves emotional and sensory experiences associated with tissue damage (Lee-Chiong et al., 2010). The findings in the current scleroderma study suggest that the level of pain intensity experienced is related to greater negative early life and current adult relational experiences. Individual differences in attachment styles may be a determining factor in relation to the coping strategies (such as self-compassion/ self-judgment) used to manage stress and the level of pain experienced. Individuals with scleroderma who have developed a dismissive style of relating may lack the capacity to trust others, and as a result, exhibit independent defensive behaviours. Such defensive behaviours may be due to underlying insecurity around gaining assistance from others, resulting in avoidance and distancing (and in the current study increased reactivity-related hyper-arousal).

The strong relationships between early nurturing experiences and pain and also between dismissive attachment (reactive hyper-arousal) and pain suggest that developing or increasing self-compassion in these individuals could be an effective strategy for managing an individual's emotions and for reducing pain experiences. Scleroderma participants in our study who engaged in self-compassion (low selfjudgment) experienced lower negative arousal and lower levels of pain. The use of self-compassion as a strategy to calm emotions and thus reduce reactive arousal has implications for individuals experiencing elevated pain, and suggests that psychotherapy approaches emphasising these aspects may be useful adjuncts to bio-therapy, physiotherapy and other therapeutic approaches aimed at helping individuals reduce the unwanted pain they are experiencing.

\section{ACKNOWLEDGEMENTS}

The researchers express their gratitude to participants and organisations who assisted in this research (the Scleroderma Association of Queensland, Scleroderma Australia and the Scleroderma Society in the United Kingdom), and to Dr Dee Bartrum for her support particularly during the early stages of the research.

\section{RefERENCES}

Ainsworth, M. D. (1985). Patterns of infant-mother attachments: antecedents and effects on development. Bulletin of the New York Academy of Medicine, 61, 771-791.

Ainsworth, M. D. S., Blehar, M. C., Waters, E., \& Wall, S. (1978). Patterns of Attachment: A Psychological Study of the Strange Situation. Hillsdale, NJ: Erlbaum.
Angelopoulos, N. V., Drosos, A. A., \& Moutsopoulos, H. M. (2001). Psychiatric symptoms associated with scleroderma. Psychotherapy and Psychosomatics, 70, 145-150.

Bakermans-Kranenburg, M. J., Juffer, F., \& Van IJzendoorn, M. H. (1998). Interventions with video feedback and attachment discussions: Does type of maternal insecurity make a difference? Infant Mental Health Journal, 19, 202-219.

Benrud-Larson, L. M., Haythornthwaite, J. A., Heinberg, L. J., Boling, C., Reed, J., White, B., \& Wigley, F. M. (2002). The impact of pain and symptoms of depression in scleroderma. Pain, 95, 267-275.

Bowlby, J. (1997). Attachment and Loss (Vol.1): Attachment. London, UK: Pimlico (Original work published in 1969).

Bowlby, J. (1998). Attachment and Loss (Vol. 2): Separation anger and anxiety. London, UK: Pimlico (Original work published in 1973).

Brewin, C. R., Firth-Cozens, J., Furnham, A., \& McManus, C. (1992). Self-criticism in adulthood and recalled childhood experience. Journal of Abnormal Psychology, 101, 561-566.

Briggs, S. R., \& Cheek, J. M. (1986). The role of factor analysis in the development and evaluation of personality scales. Journal of Personality, 54, 106-148.

Burke, A. L., Mathias, J. L., \& Denson, L. A. (2015). Psychological functioning of people living with chronic pain: A meta-analytic review. British Journal of Clinical Psychology, 5, 345-360. https://doi. org/10.1111/bjc. 12078

Burns, J.W. (2006). Arousal of negative emotions and symptom specific reactivity in chronic low back pain patients. Emotion, 6, 309-319.

Castelnuovo, G., Giusti, E. M., Manzoni, G. M., Saviola, D., Gatti, A., Gabrielli, S., ..., \& Tamburin, S. (2016). Psychological considerations in the assessment and treatment of pain in neurorehabilitation and psychological factors predictive of therapeutic response: Evidence and recommendations from the Italian consensus conference on pain in neurorehabilitation. Frontiers in Psychology, 7, 468. https://doi.org/10.3389/fpsyg.2016.00468

Chifflot, H., Fautrel, B., Sordet, C., Chatelus, E., \& Sibilia, J. (2008). Incidence and prevalence of systemic sclerosis: a systematic literature review. Seminars in Arthritis and Rheumatism, 37, 223-235.

Davies, K. A., Macfarlane, G. J., McBeth, J., Morriss, R., \& Dickens, C. (2009). Insecure attachment style is associated with chronic widespread pain. Pain, 143, 200-205.

Depue, R. A., \& Morrone-Strupinsky, J. V. (2005). A neurobehavioral model of affiliative bonding: Implications for conceptualizing a human trait of affiliation. Behavioural and Brain Sciences, 28, 313-349.

Every, G. S., \& Lating, J. M. (2002). The link from stress arousal to disease. In D. A. Meichenbaum
Pain and selfcompassion 
(Ed.), Clinical guide to treatment of the human stress response (2nd ed.). New York, NY: Springer.

Eyer, J. C., \& Thorn, B. E. (2016). The Learning About My Pain study protocol: Reducing disparities with literacy-adapted psychosocial treatments for chronic pain: A comparative behavioural trial. Journal of Health Psychology, 21, 2063-2074. https://doi.org/10.1177/1359105315570985

Fonagy, P., \& Allison, E. (2012). What is mentalization? The concept and its foundations in developmental research. In N. Midgley \& I. Vrouva (Eds.),
Richard Edward Hicks, Karen Kearney Minding the child: Mentalization-based interventions with children, young people and their families (pp. 11-34). London, UK: Routledge.

Forsythe, L. P., Romano, J. M., Jensen, M. P., \& Thorn, B. E. (2012). Attachment style is associated with perceived spouse responses and painrelated outcomes. Rehabilitation Psychology, 57, 290-300. https://doi.org/10.1037/a0030083

Freedman, R. R., \& Ianni, P. (1983). Role of cold and emotional stress in Raynaud's disease and scleroderma. British Medical Journal (Clinical Research Ed.), 287, 1499-1502.

Gatchel, R. J., Peng, Y. B., Peters, M. L., Fuchs, P. N., \& Turk, D. C. (2007). The biopsychosocial approach to chronic pain: Scientific advances and future directions. Psychological Bulletin, 133, 581624. https://doi.org/10.1037/0033-2909.133.4.581

Gilbert, P. (2001). Evolutionary approaches to psychopathology: the role of natural defences. Australian and New Zealand Journal of Psychiatry, 35, 17-27.

Gilbert, P., Baldwin, C., Irons, M. W., Baccus, J. R., \& Palmer, M. (2006). Self-criticism and selfwarmth: an imagery study exploring their relation to depression. Journal of Cognitive Psychotherapy, 20, 183-200.

Gilbert, P. (2007). Psychotherapy and Counselling for Depression (3rd ed.). London, UK: Sage.

Gilbert, P., McEwan, K., Mitra, R., Franks, L., Richter, A., \& Rockliff, H. (2008). Feeling safe and content: A specific affect regulation system. Relationship to depression, anxiety, stress and self-criticism. The Journal of Positive Psychology, 3, 182-191.

Gilbert, P. (2012). Human nature and suffering. New York, NY: Psychological Press (Original work published in 1989).

Giuggioli, D., Manfredi, A., Colaci, M., \& Ferri, C. (2010). Oxycodone in the long-term treatment of chronic pain related to scleroderma skin ulcers. Pain Medicine, 11, 1500-1503.

Griffin, D. W., \& Bartholomew, K. (1994). The metaphysics of measurement: the case of adult attachment. In K. Bartholomew \& D. P. Perlman (Eds.), Advances in personal relationships: Attachment processes in adult relationships (Vol. 5, pp. 17-52). London, UK: Kingsley.

Hammad, M., Barsky, A., \& Regestein, Q. (2001). Correlation between somatic sensation inventory scores and hyper-arousal scale scores. Psychosomatics, 42, 29-34.

Heit, S., Graham, Y., \& Nemeroff, C. B. (1999). Neurobiological effects of early trauma. The Harvard Mental Health Letter, 16, 4-6.

Hyphantis, T. N., Tsifetaki, N., Pappa, C., Voulgan, P. V., Siafaka, V., Bai, M., Alamanos, Y., Drosos, A. A., \& Mavreas, V. (2007). Clinical features and personality traits associated with psychological distress in systemic sclerosis patients. Journal of Psychosomatic Research, 62, 47-56.

International Association for the Study of Pain IASP (2012). Definition of pain. Retrieved from www.iasp-pain.org

Irons, C., Gilbert, P., Baldwin, M. W., Baccus, J. R., \& Palmer, M. (2006). Parental recall, attachment relating and self-attacking/self-reassurance: Their relationship with depression. British Journal of Clinical Psychology, 45, 297-308.

Jensen, M. P., \& Turk, D. C. (2014). Contributions of psychology to the understanding and treatment of people with chronic pain: Why it matters to all psychologists. American Psychologist, 69, 105-118. https://doi.org/10.1037/a0035641

Johnson, S. R., Hawker, G. A., \& Davis, A. M. (2005). The health assessment questionnaire disability index and scleroderma health assessment questionnaire in scleroderma trials: the evaluation of their measurement properties. American College of Rheumatology, 53, 256-262.

Juffer, F., Bakermans-Kranenburg, M. J., \& Van IJzendoorn, M. H. (2014). Attachment-based interventions: Sensitive parenting is the key to positive parent-child relationships. In P. Holmes \& S. Farnfield (Eds.), The Routledge Handbook of Attachment: Implications and Interventions (pp. 83-103). London, UK: Routledge.

Kaiser, R. S., Mooreville, M., \& Kannan, K. (2015). Psychological interventions for the management of chronic pain: A review of current evidence. Current Pain \& Headache Reports, 19, 43. https://doi. org/10.10007/s11916-015-0517-9

Kearney, K. G., \& Hicks, R. E. (2017). Self-Compassion and Breast Cancer in 23 Cancer Respondents: Is the Way You Relate to Yourself a Factor in Disease Onset and Progress? Psychology, 8, 14-26.

Keefe, F. J., Porter, L. S., \& Labban, J. (2006). Emotion regulation processes in disease-related pain: a couples-based perspective. In D. Snyder, J. Simpson, \& J. Hughes (Eds.), Emotion regulation in couples and families: pathways to dysfunction and health (pp. 207-229). Washington, DC: American Psychological Association.

Kratz, A. L., Davis, M. C., \& Zautra, A. J. (2012). Attachment predicts daily catastrophizing and social coping in women with pain. Health Psychology, 31, 278-285. https://doi.org/10.1037/a0025230

Lee-Chiong, T., Gebhart, G. F., Mattay, R. A. (2010). Chest Pain. In R. J. Mason, V. C. Broaddus, T. Mar- 
tin, T. King Jr., D. Schraufnagel, J. F. Murray, \& J. A. Nadel (Eds.), Murray and Nadel's Textbook of Respiratory Medicine (5th ed., Vol. 1, pp. 647660). Philadelphia, PA: Saunders Elsevier.

Lumley, M. A., Cohen, J. L., Borszcz, G. S., Cano, A., Radcliffe, A. M., Porter, L., Schubiner, H., \& Keefe F. J. (2011). Pain and emotion: A biopsychosocial review of recent research. Journal of Clinical Psychology, 67, 942-968. https://doi. org/10.1002/jclp.20816

Martinez, M. P., Miro, E., Sanchez, A. I., Mundo, A., \& Martinez, E. (2012). Understanding the relationship between, attachment style, pain, appraisal and illness behaviour in women. Scandinavian Journal of Psychology, 53, 54-63.

McWilliams, L. A., Cox, B. J., \& Enns, M. W. (2000). Impact of adult attachment styles on pain and disability associated with arthritis in a nationally representative sample. The Clinical Journal of Pain, 16, 360-364.

Mikulincer, M., \& Shaver, P. R. (2007). Attachment in adulthood: Structure dynamics and change. New York, NY: Guilford Press.

Miller, H., Rehberger, P., Gunther, C., \& Schmitt, J. (2012). Determinants of disability, quality of life and depression in dermatological patients with systemic scleroderma. British Journal of Dermatology, 166, 343-353.

Neff, K. D. (2003a). Self-compassion: An alternative conceptualization of a healthy attitude toward oneself. Self and Identity, 2, 85-101.

Neff, K. D. (2003b). The development and validation of a scale to measure self-compassion. Self and Identity, 2, 223-250.

Neff, K. D., Kilpatrick, K. L., \& Rude, S. S. (2007). Selfcompassion and adaptive psychological functioning. Journal of Research in Personality, 41, 139-154.

Pace, T., Negi, L. T., Ademe, D., Cole, S., Sivilli, T., Brown, T., Issa, M. J., \& Raison, C. L. (2009). Effect of compassion meditation on neuroendocrine, innate immune and behavioural responses to psychosocial stress. Psychoneuroendocrinology, 34, 87-98.

Phillips, J. R., Hopwood, B., Stroud, R., Dieppe, P. A., \& Toms, A. D. (2017). The characterisation of unexplained pain after knee replacement. British Journal of Pain, 11, 203-209.

Pope, J. (2011). Measures of systematic sclerosis (scleroderma). Arthritis Care and Research, 63, S98-S111. https://doi.org/10.1002/acr.20598

Rainville, P., Boa, Q. V. H., \& Chretien, P. (2005). Painrelated emotions modulate experimental pain perception and autonomic responses. Pain, 118, 306-318.

Richter, A., Gilbert, P., \& McEwan, K. (2009). Development of an early memories of warmth and safeness scale and its relationship to psychopathology. Psychology and Psychotherapy: Theory, Research and Practice, 82, 171-184.
Romeo, A., Tesio, V., Castelnuovo, G., \& Castelli, L. (2017). Attachment style and chronic pain: Toward an interpersonal model of pain. Frontiers in Psychology, 8, 284. https://doi.org/10.3389/fpsyg.2017.00284

Sachs-Ericsson, N., Blazer, D., Plant, A. E., \& Arnow, B. (2005). Childhood sexual and physical abuse and the 1-year prevalence of medical problems in the national comorbidity survey. Health Psychology, 24, 32-40.

Schore, A. N. (1994). Affect regulation and the origin of the self: The neurobiology of emotional development. Hillsdale, NJ: Erlbaum.

Schore, A. N. (2002). Dysregulation of the right brain: a fundamental mechanism of traumatic attachment and the psychopathogenesis of posttraumatic stress disorder. Australian and New Zealand Journal of Psychiatry, 36, 9-30.

Selye, H. (1976). Forty years of stress research: Principal remaining problems and misconceptions. Canadian Medical Association Journal, 115, 53-56.

Simm, R., \& Barker, C. (2018). Five years of a community pain service solution-focused pain management programme: Extended data and reflections. British Journal of Pain, 12, 113-121.

Simpson, J. A., \& Rholes, W. S. (Eds.) (1998). Attachment theory and close relationships. New York, NY: Guilford Press.

Steen, V. D., \& Medsger, T. A. (1997). The value of the Health Assessment Questionnaire and special patient-generated scales to demonstrate change in systemic sclerosis patients over time. Arthritis Rheumatology, 40, 1984-1991.

Tan, G., Jensen, M. P., Thornby, J., \& Sloan, P. A. (2008). Negative emotions, pain, and functioning. Psychological Services, 5, 26-35.

Thakkar, R. R., \& McCanne, T. R. (2000). The effects of daily stressors on physical health in women with and without a childhood history of sexual abuse. Child Abuse \& Neglect, 24, 209-221.

Van der Kolk, B. A., \& Greenberg, M. S. (1987). The psychobiology of the trauma response: hyperarousal, constriction and addiction to traumatic reexposure. In B. A. Van der Kolk (Ed.), Psychological trauma (pp. 63-88). Washington, DC: American Psychiatric Publishing.

Williams-Judge, S. L. (2011). Pain perspective in scleroderma. The Rheumatologist. Retrieved from www.the-rheumatologist.org/article/pain-perspective-in-scleroderma/

Wren, A., Somers, T. J., Wright, M. A., Goetz, M. C., Leary, M. R., Fras, A. M., Huh, B. K., Rogers L. L., \& Keefe, F. J. (2011). Self-compassion in patients with persistent musculoskeletal pain: Relationship of self-compassion to adjustment to persistent pain. Journal of Pain and Symptom Management, 43, 759-770.
Pain and selfcompassion 